II Congresso Brasileiro de

Fluidodinâmica Computacional

27 a 29 de Junho de 2018

Rio de Janeiro, RJ

\title{
VAZAMENTO DE GÁS NATURAL EM APARTAMENTO: SIMULAÇÃO NUMÉRICA E ANÁLISE DE RISCO
}

\author{
J. V. CUNHA OLIVEIRA ${ }^{1}$, E. M. CABRAL ${ }^{2}$ e F. F. D. A. MEIRA ${ }^{1}$ \\ ${ }^{1}$ Instituto Federal da Paraíba, Departamento de Construção de Edifícios \\ ${ }^{2}$ Universidade Federal de Campina Grande, Departamento de Engenharia Mecânica \\ E-mail para contato: joaovictorwo@gmail.com
}

\begin{abstract}
RESUMO - A Fluidodinâmica Computacional (CFD) é uma técnica quem vem sendo utilizada na construção civil em diversas aplicações, a exemplo da previsão de riscos de acidentes no interior de ambientes, pela propagação de gases com potencial explosivo, decorrentes de vazamento em tubulações. O presente estudo tem como objetivo analisar suscintamente o vazamento de gás natural em um apartamento residencial, avaliando possíveis riscos e propondo soluções para o problema. A simulação evidenciou que, para o regime permanente adotado, a sala, área de serviço e o hall de entrada exibiram frações volumétricas de gás dentro da faixa de concentração de risco de explosões.
\end{abstract}

\section{INTRODUÇÃO}

A simulação numérica em CFD teve um desenvolvimento impressionante nas últimas décadas. Inicialmente, como um instrumento para análise de problemas físicos em nível de investigação científica e, atualmente, como uma ferramenta poderosa para a solução de importantes problemas aplicados da engenharia (Maliska, 1995). A técnica vem sendo adotada em diversas vertentes industriais, tais como: aerodinâmica veicular e aeroespaciais, hidrodinâmica de navios, turbinas, bombas hidráulicas, trocadores de calor, processos químicos, meteorologia, biomedicina, dentre outras (Versteeg \& Malalasekera, 1995).

No campo da construção civil, com ênfase nos ambientes das edificações, o cuidado com o dimensionamento estético, acústico, térmico e de segurança tornou-se mais presente na atualidade, bem como a observação do clima e da temperatura (Oliveira et al., 2017). Com isto, este estudo visou a análise da propagação de gás natural para identificação das áreas de risco de acidentes por explosões nos ambientes residenciais.

As simulações em CFD voltadas para o ambiente construído podem ser divididas em estudos externos e internos. Nos estudos de fluxos internos, as maiores aplicações são voltadas para análises de qualidade do ar, ventilação artificial, sistemas de exaustão, riscos de incêndio, bem como predição da ventilação natural (Gaspar; Barroca; Pitarma, 2003 apud Trindade et al., 2010).

O presente estudo analisa o vazamento em uma tubulação de gás natural utilizando como base as simulações numéricas adotando-se prováveis condições iniciais e de contorno, o que proporciona confiabilidade quanto às informações obtidas ao final do estudo. Nesse sentido, a pesquisa em questão motivou-se mediante a necessidade para adotar-se medidas de 


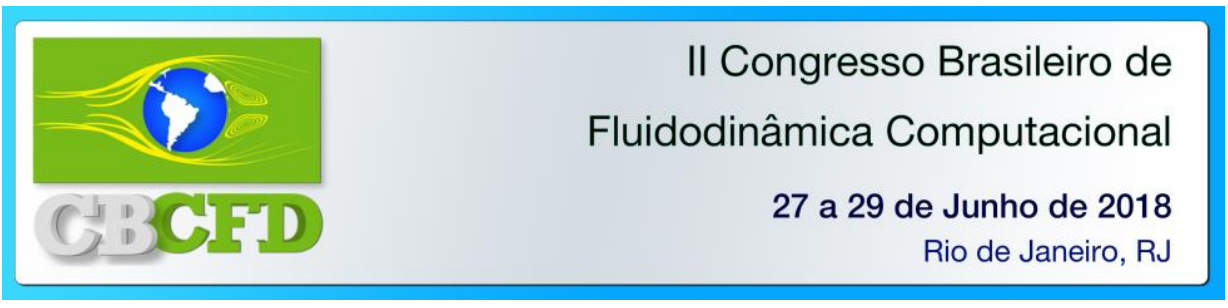

segurança no projeto de apartamento em um edifício, e tem como objetivo avaliar possíveis riscos causados pela má ventilação, e concentração do gás natural na situação de vazamento, propondo soluções para o problema.

\section{METODOLOGIA}

Para a análise do escoamento foi utilizado o programa CFX, da plataforma Ansys® 17.0. O problema em análise consiste de um apartamento de caráter unifamiliar, com área total de $75 \mathrm{~m}^{2}$ e pé-direito de 2,80m. Dentro deste domínio, estão contidos Hall de entrada, sala de estar, copa/cozinha, quarto, suíte, BWC social e área de serviço (Figura 1-a). Além disso, na Figura 1-b são apresentadas as 9 janelas (destacadas em vermelho) distribuídas nos diferentes cômodos (à exceção da sala, com duas janelas), assim como a região de entrada do gás na cozinha do apartamento.
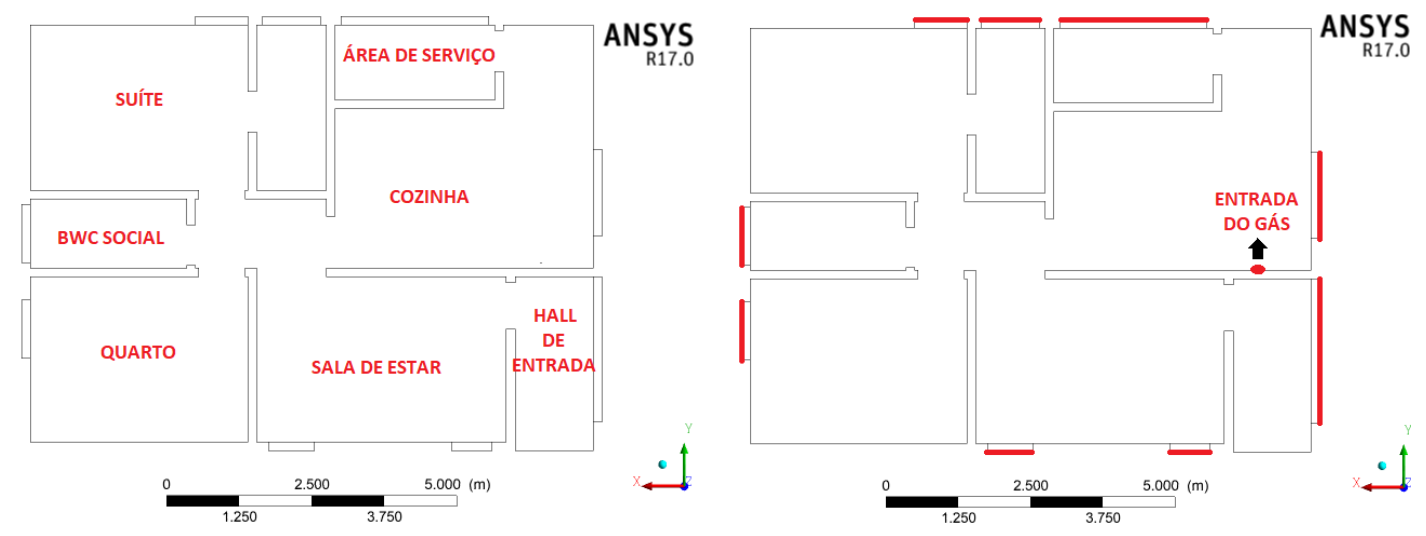

Figura 1 - Nomenclatura dos ambientes (a-esquerda); Esquadrias e entrada do gás (b-direita)

A malha gerada para a simulação numérica, depois de refinada de modo a obter a não interferência nos resultados, possui 669.344 nós e 3.520.069 elementos. O modelo utilizado foi o Euleriano, com ar e gás natural tratados como fases contínuas e o sistema de turbulência foi o k-Epsilon. O gás natural é composto de uma mistura ideal de composição e frações volumétricas descritas na Tabela 1. As propriedades das frações presentes na mistura de gás se deram de acordo com o default. A entrada do gás (Figura 1-b) ocorre a uma velocidade de $20 \mathrm{~m} / \mathrm{s}$ e $25^{\circ} \mathrm{C}$, por um orifício com diâmetro de $4 \mathrm{~cm}$, distando $50 \mathrm{~cm}$ do piso e $90 \mathrm{~cm}$ de afastamento da alvenaria lateral, no interior da cozinha. Para as paredes foi determinada a condição de não-deslizamento do fluido. O escoamento ocorre em regime permanente, e as janelas foram configuradas como bordas do tipo opening (com 99\% de ar, e 1\% de gás natural) à pressão atmosférica e temperatura do ar a $25^{\circ} \mathrm{C}$.

Tabela 1 - Composição do gás natural em mistura fixa ideal

\begin{tabular}{c|c}
\hline Componente & Fração Volumétrica \\
\hline Metano & 0.9 \\
\hline Etano & 0.07 \\
\hline Propano & 0.03 \\
\hline
\end{tabular}




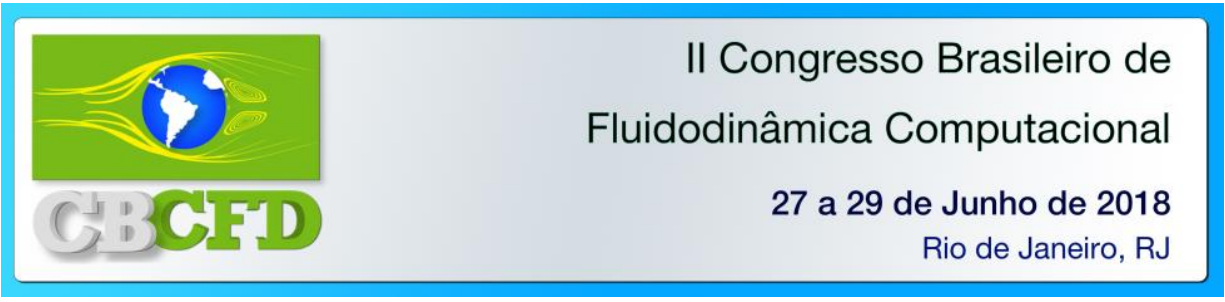

\section{RESULTADOS E DISCUSSÃO}

Na Figura 2 estão apresentados os resultados para velocidade do gás (2-a) e fração volumétrica (2-b), na altura $150 \mathrm{~cm}$. As análises dos resultados apresentados permitem afirmar que no quarto e na suíte, houve maior concentração de gás, sem dissipação eficaz do mesmo pelas janelas.
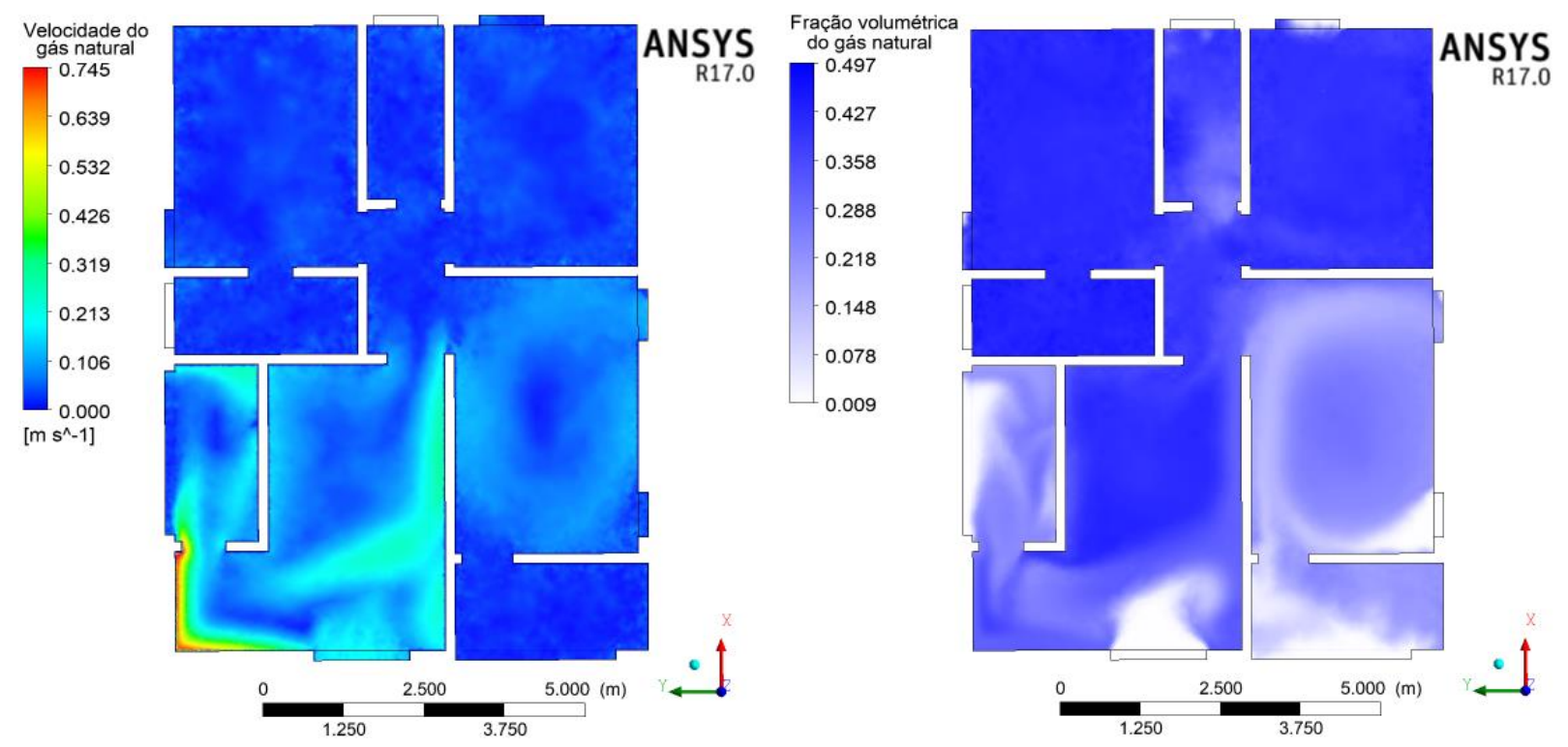

Figura 2 - Perfil de velocidade do gás natural (a-esquerda); Perfil de fração volumétrica do gás natural (b-direita)

A Figura 3 evidencia as linhas de corrente do fluxo de gás natural, para a variável de velocidade. Na sala, as janelas escoaram o gás, mas a concentração do mesmo ainda é consideravelmente elevada (se encontrando entre $10 \%$ e $30 \%$ em grande parte da área, de acordo com a Figura 2-b).

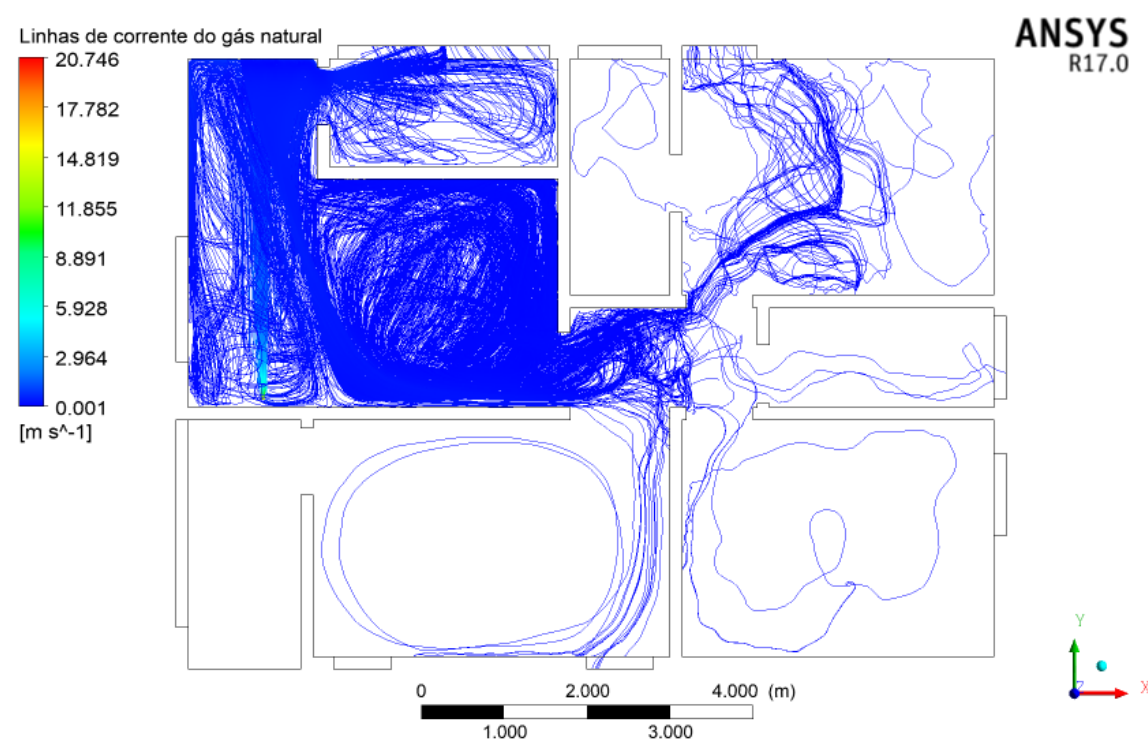

Figura 3 - Linhas de corrente para a velocidade do gás natural 


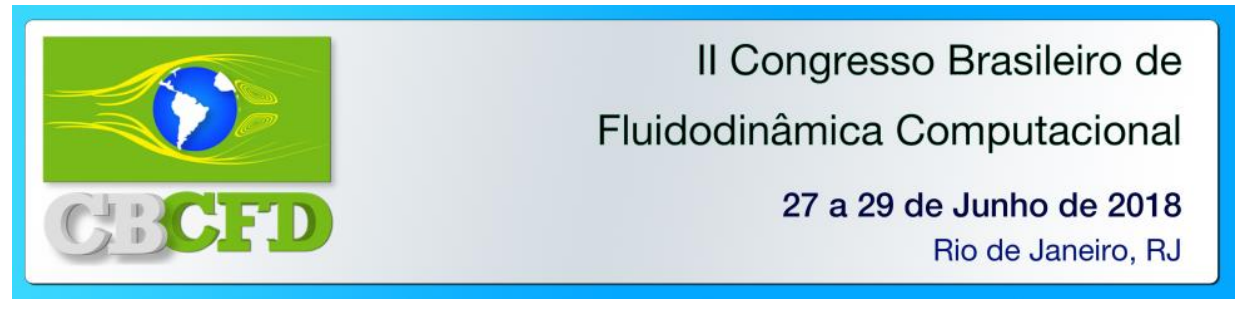

A Figura 4 apresenta os locais onde a fração de gás está entre de 0.05 e 0.15 , níveis em que há risco de explosões (Mendes, 2001). Os cômodos que exibiram risco foram a área de serviço, o hall de entrada e a sala de estar, além das janelas do banheiro da suíte, do quarto, da sala, do hall de entrada e da cozinha.

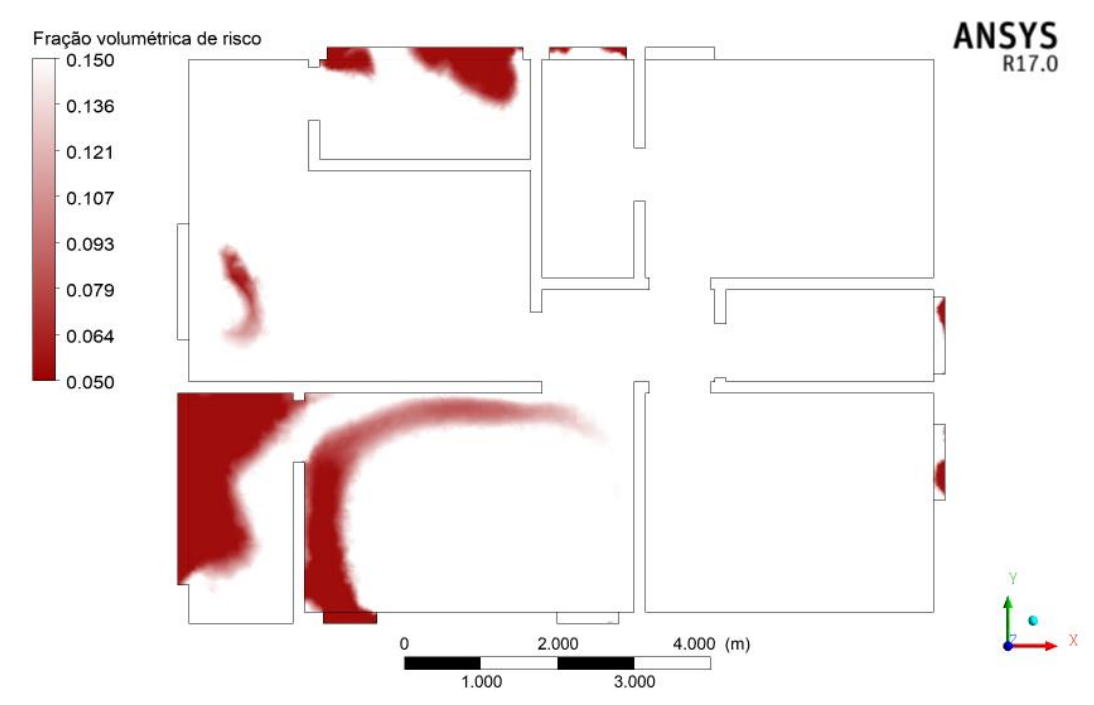

Figura 4 - Concentração de risco para vazamento de gás natural

\section{CONCLUSÕES}

Apesar de a suíte e o quarto terem apresentado as mais elevadas taxas de fração volumétrica do gás natural, a sala, área de serviço e o hall de entrada exibiram taxas dentro da faixa de concentração de risco. Tais condições foram evidenciadas para uma análise em regime permanente, o que permite entender que no estudo transiente, quando as concentrações de gás natural ainda eram menores, os primeiros cômodos também apresentariam risco de explosão.

\section{REFERÊNCIAS}

MALISKA, C. R. Transferência de calor e mecânica dos fluidos computacional. Rio de Janeiro: Livros Técnicos e Científicos, 1995.

MENDES, P. Segurança nas redes de distribuição de gás. TECNOMETAL nº 133, 2001. Disponível em <https://goo.gl/ZuCYj8>.

OLIVEIRA, J. V. C.; CABRAL, E. M.; MEIRA, F. F. D. A. Aplicação de geometria booleana, geração e refinamento de malha para modelagem fluidodinâmica computacional em um apartamento de caráter unifamiliar. In: Encontro Internacional de Jovens Investigadores, 3, 2017, Fortaleza. Anais... Fortaleza, 2017.

TRINDADE, Sileno Cirne; PEDRINI, Aldomar; DUARTE, Raimundo Nonato Calazans. Métodos de aplicação da simulação computacional em edifícios naturalmente ventilados no clima quente e úmido. Ambiente Construído (Online), Porto Alegre, v. 10, n. 4, p. 37-58, Dec. 2010. Disponível em <https://goo.gl/q1Baqk>.

VERSTEEG, H. K.; MALALASEKERA, W. An introduction to computational fluid dynamics: The finite volume method. Harlow: Longman Scientific \& Technical, 1995. 